\title{
CRIMINOLOGIA VERDE, ABUSO ANIMAL E TRÁFICO NO BRASIL: REGULAÇÃO PENAL DEFICIENTE NA PROTEÇÃO EFETIVA DO MEIO AMBIENTE
}

\author{
Luiz Gustavo Gonçalves Ribeiro ${ }^{1}$ \\ Lélio Braga Calhau ${ }^{2}$
}

Resumo: O artigo analisa, sob a ótica da criminologia verde e do direito penal ambiental, a deficiência da legislação penal brasileira no tocante ao tráfico de animais, e tem por escopo alertar o leitor para a gravidade da conduta que atenta conta a dignidade animal e para a omissão do legislador na tipificação da conduta. A pesquisa é de cunho bibliográfico e o método é o lógico-dedutivo.

Palavras-chave: Animais; tráfico; criminologia verde; direito penal.

\section{GREEN CRIMINOLOGY, ANIMAL ABUSE AND TRAFFICKING IN BRAZIL: DEFICIENT CRIMINAL REGULATION IN EFFECTIVE ENVIRONMENTAL PROTECTION}

\begin{abstract}
The article analyzes, from the point of view of green criminology and environmental criminal law, the deficiency of Brazilian criminal legislation with regard to animal trafficking, and aims to alert the reader to the seriousness of the conduct that takes into account animal dignity and the omission of the legislator in the type of conduct. The research is bibliographic and the method is logical-deductive.
\end{abstract}

Keywords: Animals; traffic; green criminology; criminal law.

\section{INTRODUÇÃO}

\footnotetext{
${ }^{1}$ Pós-Doutor pela Università degli Studi di Messina/IT. Doutor e Mestre em Direito pela UFMG. Professor de Direito Penal do curso de Graduação e de Direito Penal Ambiental dos cursos de Mestrado e Doutorado em Direito Ambiental e Desenvolvimento Sustentável da Dom Hélder- Escola de Direito. Promotor de Justiça do Ministério Público do Estado de Minas Gerais.

*Endereço: Rua Rio Grande do Norte, 1473, apto 1206, Funcionários, Belo Horizonte/MG. CEP: 30130131.

*Endereço eletrônico: lgribeirobh@gmail.com

2 Doutorando em Direito Ambiental pela Dom Hélder- Escola de Direito. Mestre em Direito das Relações Sociais pela Faculdade Milton Campos. Especialista em Direito Penal pela Universidade de Salamanca (Espanha). Graduado em Psicologia pela UNIVALE. Professor de Criminologia na Fundação Escola Superior do MP-MG. Promotor de Justiça do Ministério Público do Estado de Minas Gerais.

*Endereço: Rua Odilon Braga 567/1001, Anchieta, Belo Horizonte/MG. CEP: 30310390.

*Endereço eletrônico: direitopenal@gmail.com
} 
O tráfico de animais é uma das atividades mais destrutivas contra o meio ambiente e nada aponta que o mesmo esteja diminuindo ou esteja sob controle, haja vista que a subnotificação desse tipo de conduta ilícita e a sua grande capilaridade por todo o Brasil impossibilitam sua verificação por números mais seguros e que espelham a sua triste realidade.

Além de saquear o meio ambiente brasileiro e contrabandear animais em condições totalmente insalubres dentro de malas, recipientes fechados de forma claustrofóbica, em compartimentos secretos de veículos e até dentro de roupas, os traficantes de animais movimentam uma quantidade milionária de recursos com essa ação ilícita.

Trata-se de uma atividade que é percebida por parte da população como um crime de pequena gravidade, ou até, por alguns, como um direito do ser humano extrair da natureza tudo que for necessário para o seu sustento financeiro, de forma que movimenta não só as grandes organizações criminosas com pessoas espalhadas por todo o Brasil e no exterior. Volta e meia são vistas pessoas que, às margens de rodovias federais, vendem papagaios, capturados em regiões como o sul da Bahia, para motoristas que transitam para todas as regiões do Brasil.

O problema enfrentado neste artigo é o de que a Lei Federal 9.605/98 foi um marco para a questão ambiental no Brasil, porém não conseguiu resolver a questão do tráfico e da própria dignidade animal, embora fiscalizações venham ocorrendo de forma permanente em todo o território nacional. É uma falha que está longe de ser efetivamente resolvida e perpassa pela inconsistência e desproporcionalidade da resposta penal para tais condutas.

O tema central que se abordará é o tráfico de animais e a sua resposta insuficiente penal em território brasileiro por intermédio de pesquisa bibliográfica e raciocínio lógicodedutivo, do qual se infere, como tese, a existência do tráfico de animais como nocivo ao animal não humano, como antítese, a deficiência na tutela penal desse tipo de conduta e, como síntese, a necessidade de tipificação, por ser ela nociva à fauna e ao patrimônio natural nacional, e por representar objeto nobre de tutela jurídica tendo em vista, no campo penal, o peno enquadramento do bem jurídico nos preceitos de fragmentariedade e subsidiariedade.

Neste artigo, através da Criminologia Verde, revisita-se o problema com apontamentos sobre questões antigas e recentes, que refletem o que ainda hoje é fato, ou seja, que a proteção penal e constitucional aos animais segue ainda sendo deficiente para se controlar o tráfico de animais no Brasil. Serão, outrossim, abordados aspectos de axialidade entre a criminologia 
verde, o direito penal ambiental e o tráfico de animais, bem como sobre a (não) tutela do tráfico insculpida na Lei 9605/98, conhecida como Lei de Crimes Ambientais.

O objetivo geral do texto é apontar a necessidade de promover mudanças na lei federal que rege a matéria, elevando a conduta do tráfico de animais para patamares condizentes a uma resposta proporcional e que garanta efetividade na proteção do meio ambiente.

O estudo é justificado não apenas pela proteção animal deficiente, mas também porque já se passaram mais de vinte anos da edição da Lei Federal 9.605/98 e o problema ainda perdura por uma miríade de motivos, que serão aqui tratados, mas que, como se de spoiler tratasse, dizem respeito à falta de compromisso dos representantes do Congresso Nacional no aperfeiçoamento da lei em prol da dignidade animal.

O referencial teórico aborda a ideia da proteção efetiva dos animais, que é garantida pela Constituição Federal e que é, outrossim, objeto de estudo por parte da Criminologia Verde.

\section{CRIMINOLOGIA VERDE}

Há uma divergência entre os pesquisadores sobre quando surgiu a Criminologia, como nós a conhecemos. Para alguns, ela teria se originado com a Escola Positiva; para outros, na Escola Clássica, cerca de cem anos antes, e, para Eugênio Raul Zaffaroni, ainda bem antes, com o advento da Inquisição e sua perseguição contra as bruxas e os hereges (CALHAU, 2020).

Independente, porém, de qual linha se siga sobre sua origem, não há muita dúvida de que a Criminologia focou, nas suas fases embrionárias, nas cidades e nos que hoje conhecemos como crimes de rua (street crimes). Foi Edwin Sutherland, em seu discurso de 27 de dezembro de 1939, que, como presidente da Associação Norte-Americana de Sociologia, rompeu com esse paradigma e apontou a existência dos chamados crimes do colarinho branco (white collar crimes), que não era objeto de investigação por parte da Criminologia até aquele momento.

A Criminologia não parou por aí. Sutherland e muitos tiveram os seus caminhos abertos no início do século XX pela Escola de Chicago. Depois de Sutherland, vieram muitas novas teorias e estudos, dentre os quais "a anomia" (Robert K. Merton), "subcultura criminal" (Albert K. Cohen), o "labelling approach” (por todos: Howard S. Becker) e, já nos anos 
setenta do século XX, a Criminologia Crítica, que se ergue com grande força no Brasil na atualidade.

Todavia, embora o paradigma crítico tenha se fortalecido muito, com a denúncia, mais do que justa, da desigualdade do sistema capitalista e o seu caráter criminógeno, surgiram, numa evolução natural, novas abordagens parciais, durante os anos setenta e oitenta, que estão crescendo muito mundo afora, e que conhecemos como as chamadas "criminologias pósmodernas".

Dentre elas, podemos citar as seguintes criminologias: Feminista, Cultural, Verde (meio ambiente), dos Condenados, Rural, Queer, etc, que são decorrentes dos novos estudos, que surgiram nas últimas décadas, e não buscam uma explicação universal para o fenômeno do crime, mas uma análise parcial de problemas, sob novos enfoques, que a própria Criminologia Crítica, por sua extensão, talvez não houvesse aberto espaço.

Dentre as acima citadas, interessa-nos, no presente artigo e em especial, a Criminologia Verde (Green Criminology), apontada por alguns como surgida no início dos anos noventa, mas que segundo Nigel South já apresentava suas ideias em textos esparsos algumas décadas antes (CALHAU, 2020).

A Criminologia Verde busca resgatar a proteção efetiva do meio ambiente não se limitando apenas ao estudo dos crimes ambientais, definidos na órbita de cada país.

A Criminologia Verde ${ }^{3}$ busca, outrossim, estudar as leis, os danos ambientais e a regulação ambiental, com o objetivo de angariar respostas mais adequadas para a proteção do meio ambiente, haja vista que muitos fatos danosos socialmente, em questões ambientais, podem estar acobertados, inclusive, por legislações ${ }^{4}$ internas de alguns países, o que não exclui o seu caráter de dano social.

Na lição de Angus Nurse (2016) o debate é sempre algo muito intenso na Criminologia Verde:

O crime verde é uma área que se move rapidamente e um tanto contestada, na qual acadêmicos, legisladores e profissionais frequentemente discordam não apenas sobre

\footnotetext{
${ }^{3}$ Resumidamente, pode-se dizer que a proposta estruturante da Criminologia Verde tenciona o debate no que tange à responsabilidade humana diante da fragilidade da natureza e da garantia das próximas gerações herdarem um mundo capaz de ser habitado de forma equilibrada. O que contribui sobremaneira para a materialização da previsão forma da constituição de tutela e preservação das presentes e futuras gerações (JUNG; DAMACENA, 2018).

${ }^{4}$ Isso ocorre, em muitos casos, por conta de lobbies extremamente poderosos como os dos setores de minério, petróleo, agronegócio etc, que mantém sistematicamente pressão sobre os legisladores, em muitas situações contribuindo com valores expressivos para as campanhas ou fornecendo apoio logístico.
} 
como os crimes verdes devem ser definidos, mas também sobre: a natureza da criminalidade envolvida; soluções potenciais para problemas de crime verde; e o conteúdo e as prioridades da política. No discurso da justiça ecológica, os debates continuam sobre se os crimes verdes são mais bem tratados por meio de sistemas de justiça criminal ou por meio de mecanismos civis ou administrativos. De fato, uma discussão central dentro da criminologia verde é se o dano ambiental ao invés do crime ambiental deve ser seu foco, com a perspectiva do dano ambiental atualmente dominando o discurso criminológico verde. Em essência, há um debate fundamental em andamento sobre se os crimes verdes devem ser vistos como o foco da justiça criminal convencional e tratados pelas principais agências de justiça criminal, como a polícia, ou se eles devem ser considerados como estando fora do normal. $\mathrm{O}$ argumento para esta perspectiva de dano é dominado pela natureza muitas vezes transnacional dos 'crimes' ambientais, sua localização dentro de departamentos de política ambiental do governo em vez de justiça criminal e o fato de que os danos ambientais são frequentemente tratados por agências ambientais especializadas (in) devidamente constituídas (e com recursos) para lidar com as especificidades do crime verde. Deve-se, no entanto, notar desde o início que muitos danos ambientais são de natureza regulamentar, em vez de serem categorizados como crimes. Dito de outra forma, muito do que podemos pensar como crime verde não é de fato definido como crime e é tratado de outra forma que não por agências de justiça criminal (NURSE, 2016, p. 9) ${ }^{5}$.

A preocupação da Criminologia Verde, então, não é somente com o crime, mas com o próprio dano social e até com os atos legais que provoquem danos ambientais. Vê-se que o estudo da Criminologia Verde afasta-se do foco único da proibição da lei para gravitar, ainda, ao redor do dano social. De fato, a proteção efetiva do meio ambiente é o seu fim e sabemos a força que as corporações, como as mineradoras, possuem junto aos governos para interferirem, através de lobistas, na produção legislativa de diversos países.

Na visão de Boeira e Colognese (2017) a Criminologia Verde busca, então, um novo foco para o crime ambiental. Nesse sentido, discorrem, sob o novo ramo da criminologia, ser “[...] necessário transcender a Criminologia tradicional para encontrar uma nova base conceitual que capte de forma mais adequada o caráter dessas práticas, cujos danos são

\footnotetext{
${ }^{5}$ Texto original: "Green crime is a fast-moving and somewhat contested area in which academics, policymakers and practitioners frequently disagree not only on how green crimes should be defined but also on: the nature of the criminality involved; potential solutions to problems of green crime; and the content and priorities of policy. Within ecological justice discourse, debates continue over whether green crimes are best addressed through criminal justice systems or via civil or administrative mechanisms. Indeed, a central discussion within green criminology is that of whether environmental harm rather than environmental crime should be its focus, with the environmental harm perspective currently dominating green criminological discourse. In essence, there is ongoing fundamental debate over whether green crimes should be seen as the focus of mainstream criminal justice and dealt with by core criminal justice agencies such as the police, or whether they should be considered as being beyond the mainstream. The argument for this harm perspective is dominated by the often transnational nature of environmental 'crimes', their location within government environmental policy departments rather than criminal justice ones and the fact that environmental harms are often dealt with by specialist environmental agencies (in)appropriately constituted (and resourced) to deal with the specifics of green offending. It should, however, be noted from the outset that much environmental harm is regulatory in nature rather than actually being categorized as crimes. Put another way, much of what we may think of as green crime is not in fact defined as crime and is dealt with other than by criminal justice agencies".
} 
incomparavelmente mais graves que os delitos castigados pela justiça penal" (BOEIRA; COLOGNESE, 2017, p. 175).

Ou seja, a questão do controle dos crimes ambientais demonstra que os danos ambientais são muito maiores que as respectivas punições, em especial, as de caráter penal. Embora os crimes ambientais sejam praticados com extrema gravidade (e, no caso do tráfico de animais, não são incomuns) e os infratores sejam multirreincidentes na mesma prática delitiva, não há uma punição penal proporcional para os danos causados pelos traficantes de animais.

Na lição de ABAD (2001):

\begin{abstract}
Não cabe dúvida de que o ser humano pode dispor dos bens e frutos que a natureza lhe proporciona para viver e melhorar a sociedade em que vive, mas sempre deverá ter em vista que, se quer seguir desfrutando desse privilégio, deve servir-se dela atuando como o que poderíamos chamara de bom administrador: poderá servir-se da madeiras das árvores, mas terá que efetuar a reposição das mesmas, para que assim as novas gerações possam seguir desfrutando dela; poderá seguir caçando ou pescando sempre que o faça por procedimentos e quantidades que permitam a manutenção das espécies, poderá seguir semeando e arando a terra, recolhendo os frutos, sempre que não leve ao esgotamento; poderá inclusive construir novas cidades, sempre que nos planos de urbanismo sejam observadas a coabitação do homem com a Natureza e nelas não seja destruída a esta última e nem as cercanias da mesma, reduzindo cada vez mais o espaço destinado ao habitat natural, tão necessário para a vida humana (ABAD, 2001, p. 97).
\end{abstract}

Ou seja, há uma série de ataques contra a natureza na história da humanidade que não só não foram evitados, como também, mesmo já estando previstos na legislação civil e penal das últimas décadas, não receberam a punição proporcional aos danos ambientais causados ao meio ambiente. A efetividade nas punições proporcionais para os crimes ambientais é, nesse sentido, um dificultador para que as condutas sejam reprimidas de forma eficiente.

\title{
3 CRIMINOLOGIA VERDE E O ABUSO ANIMAL
}

Dentre as grandes preocupações da Criminologia Verde nas últimas décadas, a questão do abuso $^{6}$ animal é um de seus núcleos de atuação. Pessoas no mundo todo se dedicam ao seu

\footnotetext{
${ }^{6} \mathrm{O}$ abuso ocorrente na indústria que utiliza animais como matéria prima da moda pode partir desde o próprio armazenamento do animal, privado de luz, alimentação e espaço até a própria extração da pele, que, em alguns casos, é feita com o animal ainda vivo.
} 
estudo e, de forma incompreensível, enfrentam todo o tipo de resistência contra o seu trabalho, e, em alguns casos mais graves, são até assassinados na defesa dos animais. ${ }^{7}$

Os animais vêm sendo alvos de ações predatórias do ser humano ao longo dos séculos, não sendo poucas as situações em que foram mortos apenas por esporte ou, ainda, submetidos a torturas para servirem de adornos, fato que era aceito, até mesmo pela indústria da moda, poucas décadas atrás.

Nesse contexto:

Os Animais vêm pagando com a própria vida a irracionalidade humana. Com ataques constantes à fauna, várias espécies foram dizimadas e outras se encontram em processo de extinção. Os Animais são privados de sua liberdade com o objetivo do lucro financeiro do homem que os considera como propriedade ou mercadoria, são confinados até o momento do abate, são submetidos a morte dolorosa e lenta, são constrangidos física e psicologicamente torturados em tráficos, em laboratórios e em aulas de medicina e veterinária, são forçados, castigados e maltratados em circos e lares, são alvos de descarga da ira e do mau-humor do homem, são machucados, amarrados, queimados vivos, afogados, são submetidos a todos os tipo de atrocidades, inclusive as inimagináveis. Enfim, os Animais são aqueles que pagam com a vida o progresso tecnológico, o desenvolvimento das ciências e a insensatez humana. (RODRIGUES, 2012, p. 59).

O abuso animal é um dos graves problemas enfrentados na atualidade do Brasil. Os maus tratos a animais ocorrem em todos os espectros sociais, desde casos frequentes de biocídios de animais com crueldade, ao contexto da macrocriminalidade, que possui agenda econômica e tenta legitimar, inclusive com a aprovação de leis, práticas abusivas contra os animais como a vaquejada, rodeios etc, no sentindo contrário ao movimento internacional de proteção dos animais.

Nesse sentido, Jung e Damacena (2018) externam que

a Criminologia Verde considera o abuso animal como algo amplo e multifacetário. Para a Green Criminology o abuso animal vai muito além do conceito dogmático de crime presente na criminologia convencional, entendendo-o como desde os pequenos atos de maus tratos ou negligência até aqueles que causam maiores danos aos animais. A Criminologia Verde busca estudar o abuso animal para além da tipicidade. Visa aprofundar as questões morais e sociológicas correlatas à dominação humana sobre a figura do animal (JUNG; DAMACENA, 2018, p. 144).

Em verdade, longe de se querer que o Direito Penal dê conta de todo abuso animal no Brasil, não há dúvida de que há casos bastante graves, como o corriqueiro tráfico de animais,

\footnotetext{
${ }^{7}$ Por todos, podemos citar Dian Fossey (1932-1985), zoóloga assassinada na luta pela defesa dos gorilas em Ruanda e no Congo.
} 
que demandam uma solução penal, mesmo porque podem conduzir ao desaparecimento de espécies da fauna silvestre brasileira.

Uma grande parte do abuso animal decorre ainda de uma cultura antropocêntrica de parte da população, que entende que o mundo existe para ser explorado pelos seres humanos ao seu bel prazer. Essa cultura, ainda muito presente em certos rincões brasileiros e até mesmo em grandes centros, não reconhece os animais como sujeitos de direitos ou que, em pior hipótese, devam ser respeitados por questões éticas, morais e pelos mínimos sentimentos de justiça social. ${ }^{8}$

Não são incomuns notícias de que cachorros e gatos, por exemplo, são atirados vivos em sacolas dentro de rios, ou, por puro sentimento de crueldade, mutilados ou atirados em postes de energia elétrica, enquanto iniciativas de se tentar esterilizar os cães e gatos em situação de rua são rechaçadas na maioria das cidades, por entenderem determinados políticos que isso representa jogar dinheiro fora, quando, de fato, não se trata apenas de uma situação ambiental, mas, também, de uma necessidade sanitária.

É fato, infelizmente, que os maus tratos aos animais ainda fazem parte da realidade no Brasil. E o interesse econômico, em muitos casos, como no tráfico de animais, está presente como adversário de um tratamento digno para os mesmos.

\section{DIREITO PENAL AMBIENTAL E PROTEÇÃO ANIMAL NO BRASIL}

A proteção ambiental no Brasil data de priscas eras e há muito consta em leis esparsas diversas. Na atualidade, e inspirada no artigo 225, da Constituição Federal de 1988, tem-se a Lei Federal 9.605/98, que trouxe uma série de novidades para o campo penal ambiental.

O Direito Penal Ambiental vem se desenvolvendo com um novo vigor a partir da Constituição e da Lei Federal 9.605/98, sendo uma área do conhecimento ainda nova enquanto comparada, por exemplo, ao Direito Penal Econômico.

E, curiosamente, enquanto o Direito Penal Ambiental, naquilo que toca aos grandes empreendimentos como a mineração transnacional, recebe atenção cada vez maior de autores ligados ao Direito Penal Econômico, a proteção penal dos animais segue sendo o "primo

\footnotetext{
${ }^{8}$ Nesse sentido, é triste contatarmos que no Brasil ainda estejamos longe de respeitarmos a natureza numa visão biocêntrica. Quando iniciativas nesse sentido são buscadas no âmbito legislativo, por exemplo, rapidamente as lideranças econômicas procuram neutralizar essas iniciativas ou até ridicularizar os defensores dos animais, como, por exemplo, nas iniciativas locais (ainda muito esparsas) para criação de hospitais veterinários para os animais em situação de rua.
} 
pobre" de todo o Direito Penal Ambiental. É de longe a parte do Direito Penal Ambiental que possui menos recursos e investimentos, isso para materializar o desinteresse político, para o seu desenvolvimento.

Os desafios, nesse contexto, para o Direito Penal Ambiental não são pequenos. Nesse sentido:

\begin{abstract}
No atual estado das ciências jurídico-penais, em que temos presenciado, no âmbito do direito penal ambiental, mas também em inúmeros outros espaços de normatividade do denominado direito penal secundário, o contínuo esvanecer das linhas que historicamente conferiram identidade ao direito penal, parece-nos legítimo e necessário um voltar de olhos ao resultado jurídico, à noção de ofensa a bens jurídicos. Um voltar de olhos comprometido não apenas em resgatar o significado crítico-garantista da ideia de ofensividade, mas também em desenvolver categorias capazes de atender aos desafios que o nosso tempo coloca. (D'ÁVILA, 2015 , p. 30-31).
\end{abstract}

Há um claro ponto de fricção entre o Direito Ambiental e o Direito Penal em alguns aspectos, levando a um suposto conflito de princípios que, num primeiro momento, podem ser antagônicos ou até mesmo inconciliáveis. Veja-se, a título de exemplo, situações em que a polícia é acionada diante da notícia de existência de pássaros da espécie canário da terra em cativeiro, sendo expedido, após análise jurídica, o competente mandado judicial de busca e apreensão. Posteriormente, em juízo, comprovados os fatos, o mesmo juiz que expediu o mandado, absolve o acusado sobre a tese de insignificância da conduta. Esses casos, que infelizmente ocorrem no dia a dia do foro com certa frequência, conduzem-nos a uma reflexão: como o mesmo crime, qual seja, a manutenção em cativeiro ${ }^{9}$ de pássaros da fauna silvestre brasileira, os mesmos que, no mercado ilegal, seriam vendidos por pelo menos três salários mínimos (o que já aponta que não seria um fato insignificante economicamente), seria, num único processo, na visão do Judiciário, significante penal (no momento da expedição do mandado de busca que o autorizou) e, em um segundo momento, atípico (ausência de ofensividade a bem jurídico)?

O paradoxo é o seguinte: como explicar que o juiz de direito, no caso concreto, negue vigência a uma conduta que encontra total subsunção ao crime do artigo 29 da Lei Federal 9.605/98, e, anteriormente, debruçado sobre os mesmos fatos e enquadramento típico, no

\footnotetext{
${ }^{9}$ Lei Federal 9.605/98 - Artigo 29, caput: "Matar, perseguir, caçar, apanhar, utilizar espécimes da fauna silvestre, nativos ou em rota migratória, sem a devida permissão, licença ou autorização da autoridade competente, ou em desacordo com a obtida: Pena - detenção de seis meses a um ano, e multa”.
} 
mesmo processo, entenda que o fato é penalmente relevante e expeça mandado judicial de busca e apreensão para os pássaros apreendidos?

No mesmo processo, o juiz, num primeiro momento, sobrepesa as informações e valores e faz prevalecer o princípio da proteção ambiental; porém, na sentença, afasta a aplicação dos princípios ambientais para dar aplicação a um princípio de direito penal que, ao ser aplicado, nega vigência casuística a um artigo vigente da lei brasileira de proteção ambiental.

Infelizmente e talvez pela ausência de empatia humana com a causa animal, não são poucas as situações em que animais são surripiados do seu meio e os autores, devidamente apresentados em juízo com provas diretas, são absolvidos judicialmente pela aplicação do princípio da insignificância, mais especificamente quando se trata da captura ou comercialização ilegal de animais ${ }^{10}$ da fauna silvestre.

\section{CRIMINOLOGIA VERDE E O TIPO PENAL DO ARTIGO 29 DA LEI FEDERAL 9605/98.}

A falta de efetividade da proteção dos animais no tocante ao tráfico de espécies já chamou atenção da doutrina há cerca de duas décadas, mas, infelizmente, nada foi feito pelo Congresso Nacional no reparo a esse erro, a essa omissão.

\footnotetext{
${ }^{10}$ BRASIL. TJMG. Processo: Recurso em Sentido Estrito. 1.0284.15.000553-6/0010005536-54.2015.8.13.0284 (1). Relator(a): Des.(a) Júlio Cezar Gutierrez. Data de Julgamento, p. 19 abr. 2017. "EMENTA: RECURSO SENTIDO ESTRITO - CRIME AMBIENTAL - ARTIGO 29, §1 INCISO III, DA LEI No 9.605/98 - POSSE ILEGAL DE PÁSSAROS DA FAUNA SILVESTRE - PRINCIPIO DA INSIGNIFICÂNICA APLICABILIDADE. INEXPRESSIVA LESÃO AO BEM JURÍDICO TUTELADO - RECURSO DESPROVIDO. - A conduta deve ser considerada materialmente atípica, com fulcro no princípio da insignificância, pois o fato não se revestiu de lesividade suficiente para atingir o bem jurídico tutelado pela norma, mesmo porque o réu mantinha apenas 01 (um) pássaro da fauna silvestre em cativeiro, não possui envolvimento em outros delitos contra o meio ambiente e o animal foi devolvida ao seu habitat natural sem maiores danos. - Recurso ministerial improvido. V.V. PENAL - CRIME AMBIENTAL - ARTIGO 29, $\S 1^{\circ}$, INCISO III, DA LEI No 9.605/98 - POSSE ILEGAL DE PÁSSAROS DA FAUNA SILVESTRE - PRINCIPIO DA INSIGNIFICÂNICA - INAPLICABILIDADE. - Incabível a aplicação do princípio da insignificância se o agente foi flagrado por policiais militares na posse de pássaros, cujo tipo tem como objeto de tutela a fauna silvestre nativa ou em rota migratória." E, ainda: TJMG. Apelação Criminal 1.0702.07.391765-1/001391765119.2007.8.13.0702 (1). Relator (a): Des.(a) Antônio Armando dos Anjos, p. 19 mar. 2010. "EMENTA: CRIME AMBIENTAL - FAUNA - ABSOLVIÇÃO - PRINCÍPIO DA INSIGNIFICÂNCIA - POSSIBILIDADE. 1. Ainda que o art. 225 da Constituição Federal preveja a todos os cidadãos direito a um meio ambiente ecologicamente equilibrado, impõe-se a aplicação do princípio da insignificância para absolver a conduta do agente, que mantinha em cativeiro espécimes da fauna silvestre sem a devida autorização, licença ou permissão da autoridade competente, pois restou comprovado que, além da pequena quantidade de pássaros, os mesmos não se destinavam à comercialização, não constituindo essa conduta grave ameaça ao bem jurídico tutelado. 2 . Preliminar rejeitada. Recurso provido."
} 
O traficante de animais atua com grande reprovabilidade contra o meio ambiente. Não são incomuns situações que remetem às centenas de animais em malas, compartimentos fechados de ônibus e, no que é pior, ao lucro com uma parcela, ínfima que seja, desses animais chegando vivos ao seu destino final em grandes cidades.

Sobre o traficante de animais,

ele não tem característica definida em parâmetro aos de outras esferas de atuação; porém, é o indivíduo que se posiciona como contraposto à personalidade do cidadão administrador do meio ambiente. Na verdade, esse último é o de homens de honrada cidadania que percorrem várias vezes, sem proteção adequada, longos caminhos e trilhas de nossas florestas e parques ecológicos na luta do combate ao tráfico de animais. Já o traficante corre atrás da busca ao maior lucro possível saqueando, indiscriminadamente, tantos ecossistemas quantos forem necessários na busca da obtenção de ótimos lucros oriundos de ação penal ilegal (CAMPO NETO, p. 311)

De fato, hoje se pune desproporcionalmente muito mais uma pessoa que é encontrada com um papagaio de quarenta anos de idade do que os traficantes de animais, pequenos, médios ou grandes, que se aproveitam dessa falha legislativa, para frequentarem cinco, dez ou quinze vezes o juízo criminal e receberem uma série de benefícios penais e processuais, até que, por vezes, venham a ser beneficiados com a extinção da punibilidade, diante do advento de algumas das várias formas de prescrição.

É uma situação absurda vivida diante e aos olhos do sistema, que, de mãos atadas, face à realidade de quase duas décadas alardeada pela doutrina, e que não encontra uma sensibilização efetiva por parte dos representantes do Congresso Nacional para ser corrigida. Isso possibilita que os animais, no Brasil, sejam saqueados pelos "piratas" do tráfico, tanto para venda no mercado interno, como para remessa a outros países, onde são comercializados a preços elevadíssimos.

Há de ser consignado que uma das razões que justificam a inércia do legislador na seara penal é a pseudo-justificativa de que são aplicadas multas elevadíssimas no campo administrativo contra os traficantes de animais. Todavia, conhecida é a baixa efetividade dessas multas administrativas que, embora sejam realmente elevadas, não são pagas, ora porque os infratores manejam recursos judiciais questionando-as, ora porque não possuem patrimônio em seu nome, que autorize uma medida coercitiva efetiva por parte do Estado. 
Outro ponto importante a se registrar é o das ações organizadas ${ }^{11}$ no tráfico de animais, tendo em vista a forma de estruturação dessa atividade ilícita, no que Alvarenga (2020) alerta:

\begin{abstract}
Muito mais sofisticado hoje em dia do que outrora, o tráfico de animais silvestres apresenta características de crime organizado, quais sejam: (1) articulação por grandes redes de rotas para o traslado dos animais, quer no interior, quer para o exterior do País; (2) recurso ao apoio de atores-chave no métier político, para uma proteção discreta e efetiva das atividades criminosas; (3) corrupção de atores governamentais, nomeadamente dos afetos às atividades fiscalizatórias, como fato, e nalguns casos como estratégia, que dá sustentação à prática; (4) conectividade dinâmica e sincronismo com outras atividades ilícitas, sobremodo com os tráficos de armas e de drogas; (5) estruturação hierárquica interna entre os agentes do tráfico similar à das organizações criminosas profissionais, marcada por uma divisão clara de funções e benefícios entre os participantes (pessoas hipossuficientes economicamente, em condições de vulnerabilidade sociopolítica, subordinam-se a membros com maior poderio). (ALVARENGA, 2020, p. 37).
\end{abstract}

O "pequeno traficante" acaba, em muitos casos, alimentando as organizações criminosas que operam na área seja vendendo os animais silvestres a preços enormes no mercado interno ou remetendo-os ao exterior, causando novo prejuízo para o país, para serem comercializados em outros países a preços ainda mais elevados.

Como o pequeno traficante de animais não recebe punição efetiva quase nenhuma, ele alimenta a fogueira da destruição da fauna brasileira. No caso concreto, por não existir uma punição proporcional para o traficante de animais, não são poucas as vezes em que os mesmos comparecerem 5, 10 ou 15 vezes ao juízo criminal e, como já dito, beneficiam-se de medidas despenalizadoras, isso quando não são absolvidos à luz da insignificância ou beneficiados diante da prescrição, seja da pretensão punitiva ou executória estatal.

\title{
6 O TIPO ESPECÍFICO PARA O TRÁFICO DE ANIMAIS
}

Diversas tentativas para se resolver a falha (omissão) legislativa já bastante destacada no texto foram realizadas nos últimos anos, mas nada foi aprovado efetivamente até o momento. O que se vê é um desinteresse institucionalizado de se proteger com mais rigor os animais brasileiros. Eles não votam. Não podem fazer doações de campanha. Não conseguem

11 “Assim, observa-se o caráter transfronteiriço do tráfico, fazendo-se necessária uma legislação e cooperação internacional ao combate do tráfico, bem como, sob outro prisma, analisa-se que referido comércio consiste em uma afronta ao estado de direito democrático, já que, dentre os diversos problemas por ele gerado, inclui-se o 
reclamar. Ao contrário, a mineração, por exemplo, recebe vozes de apoio e defesa por todos os lados. Onde há dinheiro, há interesse das pessoas sobre o assunto.

Dentre os diversos projetos de lei para se tentar reverter o quadro de proteção insuficiente no tocante ao tráfico de animais, originados na Câmara dos Deputados, podemos citar os seguintes: PL 3764/2020 - Autor: Professor Israel Batista - PV/DF, Célio Studart PV/CE, PL 4214/2020 - Autor: Rafael Motta - PSB/RN, PL 4162/2020 - Autor: Frei Anastacio Ribeiro - PT/PB, PL 5290/2019 - Autor: Zé Vitor - PL/MG, PL 3994/2019 - Autor: Juninho do Pneu - DEM/RJ, PL 7497/2017 - Autor: Sabino Castelo Branco - PTB/AM, PL 9242/2017 - Autor: Roberto Sales - PRB/RJ, PL 9855/2018 - Autor: Goulart - PSD/SP, entre outros. No Senado Federal, por exemplo, podemos citar, ainda o PL 4043/2020, de 03.08.20, do Senador Confúcio Moura e o PL 507/2015, do Senador Wellington Fagundes (PL/MT).. De se destacar em matéria legislativa relacionada à tutela animal, a aprovação do PL 1095, de autoria do Deputado Fred Costa (PATRIOTAS-MG) pelo plenário do Senado Federal no último dia 8 de setembro de 2020. A prática de abuso, maus-tratos, ferimento ou mutilação de cachorros e gatos poderá, se sancionado for o Projeto pelo Presidente da República, ser punida com pena de reclusão, de dois a cinco anos, além de multa e proibição de guarda. Todavia, sobre o tráfico de animais, o Projeto, agora aprovado, nada dispõe.

Como se observa, não faltam iniciativas legislativas para se aperfeiçoar a legislação ambiental, ora com propostas de majoração de penas, ora para se criar um tipo penal específico, que entendemos de melhor técnica, para o tráfico de animais. Todavia, a inércia está no "levar adiante" a criminalização efetiva da conduta.

O artigo 29 da Lei Federal 9.605/98 já reúne em seu bojo uma série de condutas diferentes; contudo, acrescentar o tráfico de animais, que possui reprovabilidade muito maior, ou entender abarcada a conduta pelos verbos "apanhar" ou "utilizar" de espécimes da fauna silvestre, é absolutamente inadequado, por não guardar similaridade com a proporcionalidade e reprovabilidade da conduta.

Nesse sentido:

O advento de um tipo penal específico para a conduta do traficante de animais facilitaria em muito a proteção do meio ambiente. Primeiro, porque passariam a ser objeto da ação do Estado (repressão) as condutas mais lesivas ao meio ambiente, pois um traficante de animais costuma ser mais agressivo ao meio ambiente que 200 possuidores de pequenos pássaros silvestres. Deve-se, ainda, reprimir primeiro o

fortalecimento das redes criminosas, ameaça à saúde populacional, desequilíbrio ecológico e sofrimento animal" (VALADA; SANTOS, 2019, p. 111). 
tráfico de animais (agindo de forma rígida na área administrativa e penal), mas devese buscar a ajuda e a conscientização da comunidade onde os animais estão inseridos, pois a realidade social não pode ser olvidada pelos legisladores (CALHAU, 2004, s.p.).

Ou seja, separar a punição dos artigos 29 e 32 (da Lei Federal 9.605/98) do tráfico de animais facilita a interpretação e a aplicação das sanções contra os traficantes de animais, evitando que sejam criadas teses jurisprudenciais equiparando a ação dos traficantes com aquelas previstas nos artigos acima, de molde a proporcionar benefícios penais e processuais inadequados para se reprimir efetivamente essa grave e reprovável conduta.

\section{CONSIDERAÇÕES FINAIS}

A Criminologia Verde estuda os danos, as leis e a regulação ambiental com o objetivo de garantir uma proteção mais adequada e efetiva para o meio ambiente.

O abuso animal é um dos ramos da Criminologia Verde mais importantes, o qual, no entanto, é sonegado por parte dos pesquisadores, os mesmos que concentram seus estudos em áreas mais atraentes para o fomento de pesquisas e pagamento de honorários, como a relativa aos desastres minerários, sendo a defesa da fauna uma área com menos recursos para investigações, notadamente.

O tráfico de animais não possui uma tipificação penal específica, o que contribui para a ação dos delinquentes, os quais, em muitos casos, atuam em redes, saqueiam a fauna brasileira e recebem uma punição penal insuficiente e desproporcional ao dano ambiental já que, como dito, à míngua de tipo penal adequado, são contemplados com eventuais ações de “apanhar ou utilizar" animais, tais como insculpidas na Lei 9605/98.

Embora nos últimos anos diversos projetos de lei tenham sido apresentados na Câmara dos Deputados ou no Senado federal propondo uma sanção mais proporcional e razoável para a comercialização de animais silvestres, efetivamente, não há interesse político de ser resolver a falha legislativa gravíssima de tratar o tráfico animal com a seriedade que o tema merece, o que se reputa indigno com o animal não humano e com a riqueza da fauna e do patrimônio natural brasileiros.

\section{REFERÊNCIAS BIBLIOGRÁFICAS}


ABAD, Jesús Urraza. Delitos contra los recursos naturales y el medio ambiente. Madrid, Laley, 2001

ALVARENGA, Luciano José. Tráfico de animais silvestres: historiografia e lógica de continuidade. Disponível na internet: https://aplicacao.mpmg.mp.br/xmlui/bitstream/handle/123456789/1281/TR\%C3\%81FICO\%2 0DE\%20ANIMAIS\%20SILVESTRES.pdf?sequence=1. Acesso em: 30 ago 2020.

BOEIRA, Luis Francisco Simões; COLOGNESE, Mariângela Matarazzo Fanfa. O papel da criminologia diante da devastação ambiental causada pela criminalidade dos poderosos. Revista Eletrônica Direito e Política, Programa de Pós-Graduação Stricto Sensu em Ciência Jurídica da UNIVALI, Itajaí, v.12, n.1, $1^{\text {o }}$ quadrimestre 2017. Disponível em: www.univali.br/direitoepolitica. Acesso em: 5 set. 2020.

BRASIL. Tribunal de Justiça de Minas Gerais. Apelação Criminal 1.0702.07.3917651/0013917651-19.2007.8.13.0702 (1). Relator (a): Des.(a) Antônio Armando dos Anjos, p. 19 mar. 2010. Disponível em: http://www.tjmg.jus.br/portal-tjmg/ Acesso em: 11 set. 2020.

BRASIL. Tribunal de Justiça de Minas Gerais. Recurso em Sentido Estrito 1.0284.15.000553-6/0010005536-54.2015.8.13.0284 (1). Relator(a): Des.(a) Júlio Cezar Gutierrez, p. 27 abr. 2017. Disponível em: http://www.tjmg.jus.br/portal-tjmg/ Acesso em: 11 set. 2020.

BUDÓ, Marília de Nardin. O caso do amianto no brasil sob a ótica da criminologia: invisibilidade e dano social. In: TRINDADE, André Karam; ESPINDOLA, Angela Araujo da Silveira; BOFF, Salete Oro (orgs.). Direito, democracia e sustentabilidade. Passo Fundo: IMED, 2015.

BUDÓ, Marília de Nardin. Criminologia e dano social: a efetivação da sustentabilidade para além do direito penal. In: TRINDADE, André Karam; ESPINDOLA, Angela Araujo da Silveira; BOFF, Salete Oro (orgs.). Direito, democracia e sustentabilidade. Passo Fundo: IMED, 2014.

CALHAU, Lélio Braga. Princípios de Criminologia, 9. ed, Rio de Janeiro, Impetus, 2020.

Da necessidade de um tipo penal específico para o tráfico de animais: razoabilidade da Política Criminal em defesa da fauna. Tese aprovada por unanimidade no $8^{\circ}$ Congresso Internacional de Direito Ambiental. São Paulo, Instituto "O Direito por um Planeta Verde", jun. 2004.

CAMPO NETO, Antônio Augusto Machado de. O tráfico de animais. Revista da Faculdade de Direito da Universidade de São Paulo, v. 106/107, jan./dez. 2011/2012, p. 307-347.

D’ÁVILA, Fábio Roberto. O ilícito penal nos crimes ambientais: algumas reflexões sobre a ofensa a bens jurídicos e os crimes de perigo abstrato no âmbito do direito penal ambiental. Revista do Ministério Publico do Rio Grande do Sul, Porto Alegre, n. 75, 2015, p. 11-33. 
FRANÇA, Karine Agatha; COLOGNESE, Mariangela Matarazzo Fanfa; BUDÓ, Marília De Nardin. O sofrimento animal como objeto da criminologia. Mostra de Iniciação Científica e Extensão Comunitária, Faculdade Meridional, p. 27-34, Passo Fundo, 2016.

GOYES, David Rodriguez; SOUTH, Nigel. Green Criminology Before 'Green Criminology': Amnesia and Absences. Disponível em: https://www.researchgate.net/publication/315589805_Green_Criminology_Before_'Green_Cr iminology'_Amnesia_and_Absences/link/5b6c688445851546c9f93e52/download. Acesso em: 10 set 2020 .

JUNG, Bruna da Rosa; DAMACENA, Fernanda Dalla Libera. Criminologia Verde e Abuso Animal: uma introdução necessária. Revista Eletrônica de Direito do Centro Universitário Newton Paiva. Belo Horizonte, n.35, maio/ago. 2018, p 134-147.

LYNCH, Michael J. Green Criminology . University of California Press. Edição do Kindle, 2017.

MAHER, Jennifer; PIERPOINT, Harriet; BEIRNE, Piers. The Palgrave International Handbook of Animal Abuse Studies. Palgrave Macmillan, London, 2017.

NURSE, Angus. An Introduction to Green Criminology and Environmental Justice. Los Angeles, SAGE, 2016.

POTTER, Gary. What is Green Criminology. Disponível em: http://www.greencriminology.org/monthly/WhatIsGreenCriminology.pdf. Acesso em: 15 set. 2020.

RODRIGUES, Danielle Tetu. O Direito e os Animais: uma abordagem ética, filosófica e normativa. 2. ed. Curitiba, Juruá, 2012.

UOL. Naja: Polícia indicia jovem picado e diz que ele traficava cobras há 3 anos. Disponível na internet: https://noticias.uol.com.br/cotidiano/ultimas-noticias/2020/08/13/cobra-naja--conclusao---investigacao.htm. Acesso em: 27 ago 2020.

VALADA, Daniela Cristina; SANTOS, José Eduardo Lourenço dos. A intervenção do direito penal no crime de tráfico de animais e a educação ambiental. Revista do Direito Público, Londrina, v. 14, n. 1, abr. 2019, p.103-120. 